\title{
SUSTAINABILITY FOR THE ACTORS OF A FOOD VALUE CHAIN: HOW TO COOPERATE?
}

\author{
G. PETIT ${ }^{1}$, G. YANNOU-LE BRIS ${ }^{2,3}$, G. TRYSTRAM ${ }^{1} \&$ A. LALLMAHOMED ${ }^{2}$ \\ ${ }^{1}$ UMR Génial, AgroParisTech, INRA, Université Paris-Saclay, France. \\ ${ }^{2}$ AgroParisTech, France \\ ${ }^{3}$ Laboratoire Genie Industriel, CentraleSupélec, Université Paris-Saclay, France
}

\begin{abstract}
To tackle sustainability issues, food value chain actors have to study the nature and objectives of the sustainable performance they want to achieve, both individually and also for the value chain as a whole. But they have different interests, goals and strategies. Consequently, if they want to cooperate on a shared device because this represents a possible solution to improve the value chain sustainability, they need to find a way to meet a minimum level of each actor expectations. This case study is about possibilities for actors of a pork value chain representative of one type of French production to cooperate in sharing sustainability improvement solutions. The sustainable impacts of the value chain comprising a shared methanation plant with externalization of $3 \%$ of heat and $1 \%$ of electricity produced are described and analyzed. The multicriteria evaluation of the value chain is based on a life cycle analysis model with associated environmental and social indicators. The behavior of the methanation plant is simulated using Methasim tool and the input/output flows of the software are bridged to the LCA model. A focus is made on comparing the sustainable performance of two scenarios (standard i.e. without methanation plant and with shared methanation plant) and on confronting results with respective expectations of various players of the value chain in terms of sustainable performance. Is sharing a methanation plant a good solution for the economic actors of the value chain? How to create cooperation between the actors of a value chain in order to increase sustainability of their products and practices? The results and analysis will focus on each actor's contribution to the sustainable footprint and values destroyed or created. New intermediate solutions can be then proposed. The discussion is about methodological ways to facilitate the cooperation and the data flows to be exchanged between value chain actors.
\end{abstract}

Keywords: actors, assessment, cooperation, food, indicators, sustainability, value chain,

\section{INTRODUCTION}

In the food value chains, it is the transformer's or the distributor's practice which casts a decision-making power over all actors [1-2]. The growing demand for organic, local, 'free' (antibiotics, GMO, etc.) products indicates the willingness of consumers and producers to favor alternative systems development. If labels and designations adapted to these offers are now a way to reduce the complexity of the consumer's decision, they propose a limited response for the actors of food value chains. Indeed, they constitute some specifications aimed at obtaining very specific characteristics (fed with grain, source of omega-3, rich in fiber, low in fat, etc.) and for which the global sustainability is not guaranteed. Indeed, the sustainability issues are multiple and the solutions adopted to meet them not only can generate other impacts, but also move some impacts from one phase to another of the life cycle. Therefore, if the implementation of labels or claims may be the starting point for the coordination of value chain actors, it cannot be sufficient to go beyond simple specifications. Moreover, the notion of a label potentially carries the same power exercised by one actor on the others as what was identified in the dominant food systems. It is precisely to meet the objective of offering a multicriteria framework and limiting the risks of transfer of impacts that Life Cycle Analysis has been developed [3-4]. In this paper, two assumptions are made: first modeling a 
value chain and its environmental, economic and social assessment offers a systemic framework that is superior to what labels offer. Indeed, it is more valuable to the value chain actors even if the complexity of its reading makes it inaccessible to the end users/consumers. The second hypothesis exposes that this kind of model offers a common basis to the value chain actors to consider a wider reality than what their usual paradigm offers and from which new cognitive knowledge will be built. For these actors to be in a position to design together improved value chain sustainability, they need to co-design their solutions. In this perspective, the associated design and decision-making activities are considered from a socio-cognitive point of view. The construction of a solution is then not only objectified for the creation of a response to technical needs but also as a process of negotiation between different parties [5]. In his works, Bucciarelli [6] defined these parties as the different disciplines that intervene in a design process. As part of this article, it is the pluralism of the various actors in the value chain that give rise to a space for negotiation. The representations offered by the value chain modeling and the assessment of its sustainability performance are then supported to create a common space for actors in the creation and coordination of knowledge, beliefs and mutual hypotheses. These two hypotheses are discussed here in the framework of an experiment that we conducted on the modeling of a French pork value chain. Its stakeholders seek to identify solutions to improve its sustainability performance. One of the solutions resulting from one of their brainstorming was the pooling of a methanation plant from a circular economy perspective within this value chain. Chapter 2 presents a synthesis of the physico-chemical phenomena involved in methanation and the socio-technical development of this technology in France. Chapter 3 illustrates the model created and the alternative scenarios considered with the integration of a methanation plant. In this chapter, we also provide the indicators used to perform the performance evaluation. Chapter 4 is the synthetic presentation of the results compared with and without methanation plant in the value chain. Chapter 5 allows us to discuss the contribution of these results to the two hypotheses. The conclusion synthesizes the contribution of this work to the validation of our hypotheses and defines the future research needs to complement the contribution presented in this article.

\section{PHYSICO-CHEMICAL PHENOMENON RELATED TO BIOGAS PRODUCTION AND SOCIO-TECHNICAL DEVELOPMENT IN FRANCE}

Methanation is a technique for the production of energy and heat by the valorization of biomass [7-8]. The organic bacteria present in the material allow the fermentation of this biomass and the production of biogas [9]. The biogas produced is a gas saturated with water and made of 50 to $70 \%$ methane, 20 to $50 \%$ carbon dioxide and a few trace compounds (NH3, N2, H2S) [10]. This biogas can then be recovered in the form of biomethane fuel, for the production of electricity and heat by cogeneration, in heat production alone using a boiler, or injected into the natural gas network after purification. During hydrolysis and acidogenesis, the complex organic matter (proteins, lipids and sugars) is first degraded to the simpler molecules (amino acids, fatty acids, glucose, nitrogenous bases) by the cellular enzymes present in the material. This step is sometimes limiting in the case of compounds that are difficult to hydrolyse, such as cellulose, starch or fats. These simple substrates are used at the time of acidogenesis by the so-called acidogenic microbial species which produce alcohols and organic acids, as well as hydrogen and carbon dioxide. Then, the methanogenesis step is carried out by microorganisms which operate under strictly anaerobic conditions [11]. They belong to the reign of the archaea and some fifty strict methanogenic species are described, all anaerobic. The production of methane is carried out by two possible routes: one from 
hydrogen and carbon dioxide by the hydrogenophilic species and the other from the acetate by the acetoclastic species.

2.1 Performance of methanation plants: factors of variability related to technologies and practices deployed

Organic fermentable inputs derived from biomass can be classified according to their methanogenic power: waste from the food industry, livestock effluents such as manure, straw, slaughterhouse water loaded with organic matter or sludge from sewage treatment plants, fermentable fraction of household refuse, etc [12]. If the slurry has a low methanogenic power, it is a substrate rich in bacteria that promotes methanation [13-15]. To ensure a satisfactory yield, it is necessary to add a mix of products with high methanogenic power, such as vegetables, the fat collected as scrap from the food industry [16-17]. Agricultural installations reuse among other things, their waste, and are based on territorial pooling models between several farms. Other inputs are added in order to obtain the best possible return in terms of electricity and heat. The nature of these inputs, which are solid or in the form of sludge, determines the dry or wet orientation of the methanation [18-19]. The technologies used differ according to the type of methanation (one or two stages, continuous or discontinuous, dry or liquid). The liquid or solid residue obtained from the fermentation can be upgraded as an organic fertilizer in substitution or in addition to conventional chemical fertilizers or in direct spreading when the spreading plan allows it (soil composition, geographical location and capacity of the soil). Beforehand, a standardization and homologation stage is necessary. If, however, the digestate cannot be recovered, it is destroyed: buried or incinerated. Cogeneration is the production of heat and electricity from biogas through a module consisting of a motor that drives an alternator [20-21]. Electrical efficiency can rise by up to 5\%, and heat output allows an overall efficiency of $85 \%$.

\subsection{Economic organization of a methanation process}

The main interest of cogeneration is the resale of electricity to the grid, which has to acquire electricity at a regulated price. It can be sold to supply households, businesses or local authorities, or it can be consumed whole or in part by production sites linked to methanation. Heat is recovered by heat exchangers and can be carried by hot water pipes to industries, public buildings, hospitals, collective dwellings or offices. It can also be directly used on the spot for feeding pig farms for example. As a result, cogeneration facilities are often located near areas where there is a need for heat energy to avoid the loss of transport energy. By reducing the use of fossil fuels, heat recovery leads to a reduction in pollutant emissions such as Sulphur dioxide and greenhouse gases. Finally, unlike other renewable energies that are sensitive to climatic variations, the cogeneration energy capacity is stable over time and space, and is subject to the stability of inputs. Fuels are easily stored and potentially available: waste from bio-industries, livestock effluents. It is therefore reasonable to assume that this is a reliable response to part of the electrical demand. As for heat, which is more difficult to transport, its use requires a physical approximation of the user activity in order to make the installation cost-effective. On the other hand, and even if rates act as incentives, the relative economic profitability of cogeneration systems depends heavily on the prices of fuels and competing energies. Under good conditions, cogeneration makes it possible to recover $35 \%$ of the primary energy from biogas in the form of electricity and up to $85 \%$ in total, taking into account 
the heat produced by the system. In France, the cost of the investment was estimated at around $€ 5700$ per electric kilowatt for an average power of $250 \mathrm{~kW}$. The Légifrance rate order of 14 December 2016 provides for the purchase of electricity for installations with a maximum electrical power of $80 \mathrm{~kW}$ or less, at a price of $175 € / \mathrm{Mwh}$; For those with an electrical power between $80 \mathrm{~kW}$ and $500 \mathrm{~kW}$, at a price of $155 € /$ Mwh. Beyond that, an invitation to tender is required. The buyback contracts are established over 20 years now and no longer 15 . There is no longer any obligation to recover the heat.

\section{PRESENTATION OF THE STUDIED SYSTEM}

\subsection{Perimeters of the compared models}

The value chain considered as a reference model describes an existing sector in which the actors involved are working to improve the sustainable characteristics of their activities and products by working on animal feed (content and proximity of supply), non-use of GMO foods, animal and human health, reduction of antibiotics and stress, increase in the cost of purchasing pigs from the farmer to take into account the efforts made and sharing the economic value created. The territorial scale considered is that of the western region of France which comprises of five administrative regions. Figure 1 shows the activities considered in our model for both scenarios: without (Scenario 1) and with methanation plant (Scenario 2). The addition of the methanation plant is represented in the Fig. 1 by the boxes colored pink. For the study, the hypothesis was made that in a sense of circular economy, the electricity and heat produced by the methanation plant are reinjected at the stages of the farm and the slaughterhouse; first because of their need for heat, and second because these two installations are supposed to be close to the methanation plant for the exchange of heat. However, the modeled methanation plant produces more electricity and more heat than necessary. Also, in the scenario 2, these flows in excess are sold at prevailing rates and used outside of our system.

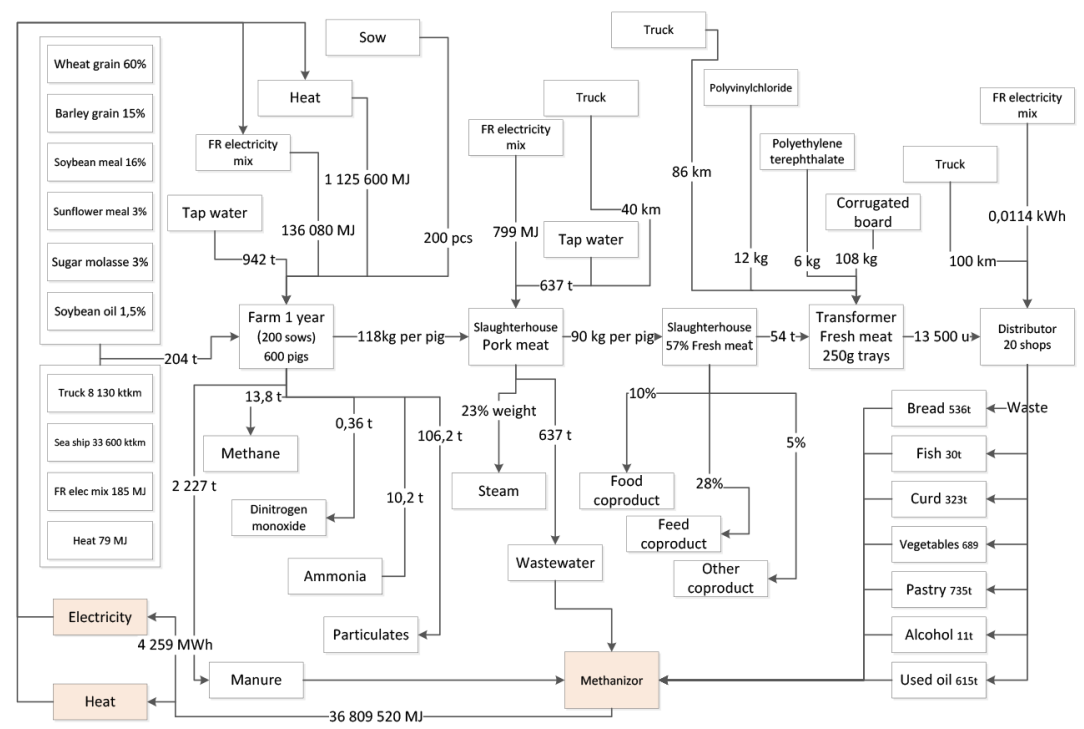

Figure 1: Perimeters of systems modeled with and without methanation plant. 
The environmental advantages of these flows production is valued as follows: in the scenario 2 , the impacts associated with the production of electricity and heat (by an average source representative of the French (mostly nuclear) energy mix) were modeled then subtracted from the impacts associated with the methanation plant scenario in order to take into account the impact avoided by the production of our facility.

The functional unit that sizes our model is the quantity of pig meat required for the production of 13,500 tray units of 6 chipolatas which involves breeding 600 pigs. The share of the activities and impacts related to the pig meat used in these chipolatas is dimensioned by the proportion of meat used per pig for their production.

\subsection{Modeling tools used}

Two modeling tools were used to conduct this study. The first one is life cycle analysis software (Simapro 8.0.5.), which allowed to evaluate and compare the environmental performance of the two scenarios. In this study, the inventory phase was carried out with real stakeholders of the French pork industry. For example, zootechnical or economic information have been collected on the ground. In order to complete this collection, the database present directly within the software databases such as EcoInvent 3 (the Swiss database) or Agri-footprint (Dutch database) were used. Finally, scientific articles and technical documentation were consulted to complete the dataset. The impact calculation phase, carried out using the Recipe 1.12 Midpoint method, widely used in the living world, made it possible to calculate specific sustainability indicators. In addition, the Methasim [22] software made it possible to size the methanation plant and its efficiency. The latter is a decision-making tool for pre-diagnosis of anaerobic digestion: it is possible to calculate the technical and economic interest of anaerobic digestion according to the choice of inputs, methanation process, purchase cost of electricity, etc. Particular attention has been paid to the nature of valuation methods of thermal energy to target the improvement provided in the tariff policy. For the purposes of this article, a minimum of data has been imposed on the tool so as to allow the latter to suggest the solutions most suited to the system studied. The characteristics chosen for the methanation plant considered in this study are: continuous liquid, the destination of the biogas: dual-fuel engine, the power of the co-generator $\left(546 \mathrm{~kW}\right.$ elec), the volume of the main digester $\left(1807 \mathrm{~m}^{3}\right)$. Figure 4 presents a synthesis of the project carried out thanks to the support of Methasim. These data are then used to calculate some of the indicators suggested by this study in the following sections.

\subsection{Repository used to assess the sustainability of scenarios}

The framework used in this study was developed by the authors in the context of work carried out prior to this study. Presentations of these papers have been made: [23]. The authors do not have the space required to go into details on the methodology implemented and therefore propose to consider these evaluation criteria simply as a reference allowing the comparison of the two scenarios.

\subsection{Data used in the model}

\section{Breeding, slaughtering and cutting phase (common to Sc1 et 2)}

In this study, the inventory phase was carried out with stakeholders in the French pork industry. In addition, the database hosted by the Simapro 8.0.5 software. EcoInvent 3 (Swiss database) 
and Agri-footprint (Dutch database) were used. Finally, scientific articles and technical documentation were consulted to complete this dataset. The impact calculation phase, carried out using the Recipe 1.12 Midpoint method, widely used in the living world, made it possible to calculate specific sustainability indicators.

\section{Sizing of incoming methanation plant streams (Sc2)}

The size of the methanation plant is defined by the nature and quantities of inputs available for its operation.

1. Determination of supply volumes from distribution

A model was constructed to establish the wastes in stores on the territory in question. In our model, we retained the losses due to the partner distributor brand of our value chain (in proportion to the area of its stores in relation to the total sales area on the territory). From the INSEE (http://www.bdm.insee.fr/bdm2/index) and FranceAgrimer (https:// www.rnm.franceagrimer.fr/prix?SAINOMPRODUIT; https://observatoire-prixmarges. franceagrimer.fr/resultats/Pages/ResultatsFilieres.aspx?idfiliere=6) databases, the volumes of French consumption and waste [24], by product categories, were defined and reported proportionally to the territory concerned and to the types of Shops located in this area [25].

2. Complementary inputs of the methanation plant

- The manure of a swine operation of 200 pigs.

- The frying oil returned to the store by consumers after use (http://www.oliobox.be/ en/solution).

- The fatty waters of a specialized porcine slaughterhouse processing 3,400 head a week.

\section{RESULTS}

Table 1 shows the values of indicators for each scenario. The Methane column expresses the gross impacts of our system for the scenario 2 while the Methane column with defalcation expresses the same impacts but alleviates the avoided impacts. It is therefore logical to find negative values.

Contributions of each actor of the value chain to the environmental performance are highlighted in the Tables 2 (scenario 1) and 3 (scenario2). The indicators, called Env1 to Env10, refer to those in Table 1.

As for Table 3, Table 4 shows the contributions per actor, but for the methanation plant scenario this time. A large number of values are common, except for electricity and heat indicators that have been replaced at farm level and the slaughterhouse by the production of the methanation plant modeled.

Finally, Tables 5 and 6 show the values of the two scenarios, control and methanation plant, but this time as a percentage of the total value of each indicator. Values may be common except for the flow of electricity and heat for the farm and the slaughterhouse, all the contribution rates change and this for all the actors.

The indicators in Table 1 show a very large disparity, particularly for environmental indicators, between the control scenario and the methanation scenarios. Impact reduction is important only when excess energy and heat are resold and used outside the perimeter. Some impacts are negative for the methanation with defalcation scenario; they correspond to a compensation of impacts related to energy and heat production by the methanation plant for the slaughterhouse and pig exploitation needs, plus the avoidance of impacts 
Table 1: Numerical results of each scenario by indicator.

\begin{tabular}{|c|c|c|c|c|}
\hline Indicator & Unity & Control & Methane & $\begin{array}{l}\text { Methane } \\
\text { with } \\
\text { deduction }\end{array}$ \\
\hline Soc1. Carcass pH & $\#$ & 5,4 & 5,4 & 5,4 \\
\hline Soc2. Transport duration & $\mathrm{h}$ & 8 & 8 & 8 \\
\hline $\begin{array}{l}\text { Soc3. Foodmiles / localness (local } \\
\text { cultures) }\end{array}$ & $\%$ & 91,0 & 91,0 & 91,0 \\
\hline Soc4. Breeder's welfare (survey) & Score 1 to 5 & 2 & 2 & 2 \\
\hline Soc5. Employees' welfare (survey) & Score 1 to 5 & 2 & 2 & 2 \\
\hline $\begin{array}{l}\text { Soc6. Biodiversity (number component } \\
\text { /formula) }\end{array}$ & $\#$ & 5,3 & 5,3 & 5,3 \\
\hline Soc7. Sensory evaluation score & Score 1 to 10 & 6,02 & 6,02 & 6,02 \\
\hline Soc8. Omega 6 / Omega 3 ratio & $\%$ & 10,7 & 10,7 & 10,7 \\
\hline Soc. 9. OGM ratio & $\%$ & 7,5 & 7,5 & 7,5 \\
\hline $\begin{array}{l}\text { Soc10. Water losses after cooking } \\
\text { (Technol quality) }\end{array}$ & $\%$ & 15,45 & 15,45 & 15,45 \\
\hline Eco1. Additional income paid to breeder & $€$ & 0 & 0 & 0 \\
\hline Eco2. Production valorisation (losses) & $\%$ & 5,9 & 5,9 & 5,9 \\
\hline Eco3. Muscles rate (economical quality) & $\%$ & 60,9 & 60,9 & 60,9 \\
\hline Eco4. Waste (losses) & $\%$ & 5,9 & 5,9 & 5,9 \\
\hline Eco5. Number of hires & \# & 0 & 0 & 0 \\
\hline Eco6. Additional work hours (-) & $\mathrm{h}$ & 0 & 0,5 & 0,5 \\
\hline Eco7. Variation of labor cost & $€$ & 0 & 0 & 0 \\
\hline Eco8. Short-term investment & $€ / \mathrm{t}$ & 0 & 0 & 0 \\
\hline Eco9. Long-term investment & $€ / \mathrm{t}$ & 0 & 20 & 20 \\
\hline $\begin{array}{l}\text { Eco10. Variation of manuf. cost per } \\
\text { product }\end{array}$ & $€$ & 0 & 43,5 & 43,5 \\
\hline Env.1. Climate change & $\mathrm{kg} \mathrm{CO}_{2}$ eq & $\begin{array}{l}132 \\
162\end{array}$ & 128418 & -1558775 \\
\hline Env2. Terrestrial acidification & $\mathrm{kg} \mathrm{SO}_{2} \mathrm{eq}$ & 5034 & 5023 & 943 \\
\hline Env. 3 Freshwater eutrophication & $\mathrm{kg} P$ eq & 53 & 53 & 47 \\
\hline Env4. Human toxicity & $\mathrm{kg} \mathrm{1,4-DB} \mathrm{eq}$ & $\begin{array}{l}225 \\
389\end{array}$ & 220041 & -1825380 \\
\hline Env5. Freshwater ecotoxicity & kg 1,4-DB eq & 766 & 762 & -934 \\
\hline Env6. Marine ecotoxicity & $\mathrm{kg} \mathrm{1,4-DB} \mathrm{eq}$ & $\begin{array}{l}102 \\
937\end{array}$ & 101246 & -530181 \\
\hline Env7. Agricultural land occupation & $\mathrm{m}^{2} \mathrm{a}$ & $\begin{array}{l}325 \\
076\end{array}$ & 325076 & 325076 \\
\hline Env8. Urban land occupation & $\mathrm{m}^{2} \mathrm{a}$ & 192 & 192 & 192 \\
\hline Env9. Water depletion & $\mathrm{m}^{3}$ & 2582 & 3170 & -4220 \\
\hline Env10. Fossil depletion & $\mathrm{kg}$ oil eq & 20134 & 18905 & -512980 \\
\hline
\end{tabular}


Table 2: Contribution results (absolute values) by actor, by indicator, control scenario.

\begin{tabular}{lllllll}
\hline $\begin{array}{c}\text { Control } \\
\text { scenario }\end{array}$ & Sum & Distribution & Transformation & Slaughterhouse & $\begin{array}{l}\text { Pigs to } \\
\text { slaughter }\end{array}$ & Feed \\
\hline Env1 & 132,162 & 1186 & 3230 & 3812 & 53,637 & 70,298 \\
Env2 & 5034 & 5 & 14 & 12 & 3600 & 1404 \\
Env3 & 53 & 0 & 0 & 0 & 10 & 42 \\
Env4 & 225,389 & 6959 & 20,849 & 5041 & 22,698 & 169,841 \\
Env5 & 766 & 8 & 21 & 4 & 299 & 434 \\
Env6 & 102,937 & 6159 & 17,482 & 1707 & 7213 & 70,376 \\
Env7 & 325,076 & 16 & 148 & 0 & 37,380 & 287,531 \\
Env8 & 192 & 51 & 85 & 0 & 0 & 56 \\
Env9 & 2582 & 4 & 18 & 247 & 921 & 1392 \\
Env10 & 20,134 & 424 & 1087 & 1128 & 4759 & 12,736 \\
\hline
\end{tabular}

Table 3: Contribution results (absolute values) by actor, by indicator, methanation plant scenario.

\begin{tabular}{lllllll}
\hline $\begin{array}{l}\text { Methanation } \\
\text { plant } \\
\text { scenario }\end{array}$ & \multicolumn{1}{c}{ Sum } & Distribution & Transformation & Slaughterhouse & $\begin{array}{l}\text { Plaughter } \\
\text { slaugh }\end{array}$ & Feed \\
\hline Env1 & 128,418 & 1186 & 3230 & 719 & 52,986 & 70,298 \\
Env2 & 5023 & 5 & 14 & 3 & 3598 & 1404 \\
Env3 & 53 & 0 & 0 & 0 & 10 & 42 \\
Env4 & 220,041 & 6959 & 20,849 & 175 & 22,217 & 169,841 \\
Env5 & 762 & 8 & 21 & 0 & 299 & 434 \\
Env6 & 101,246 & 6159 & 17,482 & 167 & 7062 & 70,376 \\
Env7 & 325,076 & 16 & 148 & 0 & 37,380 & 287,531 \\
Env8 & 192 & 51 & 85 & 0 & 0 & 56 \\
Env9 & 3170 & 4 & 18 & 836 & 919 & 1392 \\
Env10 & 18,905 & 424 & 1087 & 121 & 4538 & 12,736 \\
\hline
\end{tabular}

related to the production of surplus heat and energy. This energy produced comes out of our system; it is resold and used outside our system that is not produced by an average French mix. In consequence, the difference is expected to be much less striking between the control and the simple methanation scenario than between the control and the methanation with defalcation scenario. Some indicators remain unchanged. This is the case, for example, with the occupation of urban land. The size of the various installations in the value chain does not vary between the control and methanation plant scenarios because the methanation plant is installed on existing farms and does not necessarily require an expansion of agricultural areas or new urban areas. A very large part of the social and economic indicators remain the same between the different scenarios. For example, the 
Table 4: Contribution results (percentage) by actor, by indicator, scenario 1 .

\begin{tabular}{lllllll}
\hline $\begin{array}{c}\text { Control } \\
\text { scenario }\end{array}$ & Sum $(\%)$ & Distribution & Transformation & Slaughterhouse & $\begin{array}{l}\text { Pigs to } \\
\text { slaughter }\end{array}$ & Feed \\
\hline Env1 & 100 & 0.9 & 2.4 & 2.9 & 40.6 & 53.2 \\
Env2 & 100 & 0.1 & 0.2 & 0.2 & 71.5 & 27.9 \\
Env3 & 100 & 0.2 & 0.5 & 0 & 18.2 & 80.7 \\
Env4 & 100 & 3.1 & 9.2 & 2.2 & 10 & 75.3 \\
Env5 & 100 & 1.1 & 2.8 & 0.5 & 39 & 56.5 \\
Env6 & 100 & 6 & 17 & 1.7 & 7 & 68.5 \\
Env7 & 100 & 0 & 0 & 0 & 11.5 & 88.4 \\
Env8 & 100 & 26.8 & 44.1 & 0 & 0 & 29.1 \\
Env9 & 100 & 0.1 & 0.7 & 9.6 & 35.7 & 53.9 \\
Env10 & 100 & 2.1 & 5.3 & 5.6 & 23.5 & 63.2 \\
\hline
\end{tabular}

Table 5: Contribution results (percentage) by actor, by indicator, scenario 2 .

\begin{tabular}{lcccccc}
\hline $\begin{array}{l}\text { Methanation } \\
\text { plant scenario }\end{array}$ & & & \multicolumn{3}{c}{$\begin{array}{l}\text { Pigs to } \\
\text { slaughter }\end{array}$} & Feed \\
\hline Env1 & 100 & 0.9 & 2.5 & 0.6 & 41.3 & 54.7 \\
Env2 & 100 & 0.1 & 0.2 & 0.1 & 71.6 & 27.9 \\
Env3 & 100 & 0.2 & 0.5 & 0 & 18.2 & 80.7 \\
Env4 & 100 & 3.1 & 9.5 & 0.1 & 10.1 & 77.1 \\
Env5 & 100 & 1.1 & 2.8 & 0 & 39.2 & 56.8 \\
Env6 & 100 & 6.1 & 17.2 & 0.2 & 7.1 & 69.5 \\
Env7 & 100 & 0 & 0 & 0 & 11.5 & 88.4 \\
Env8 & 100 & 26.8 & 44.1 & 0 & 0 & 29.1 \\
Env9 & 100 & 0.1 & 0.5 & 26.4 & 29 & 44 \\
Env10 & 100 & 2.2 & 5.2 & 0.6 & 24.1 & 67.3 \\
\hline
\end{tabular}

$\mathrm{pH}$ of the carcass used here to characterize animal welfare does not vary between the two scenarios. The introduction of the methanation scenario does not necessarily imply an improvement in animal welfare compared to control. The same applies to the transport of live animals between the pig exploitation and the slaughterhouse. With the introduction of the methanizer, the model considered the same agricultural exploitation, located at the same distance from the slaughterhouse compared to the control scenario. In this case, the indicator does not change. Among the economic indicators, the waste rate remains the same for the actors in the value chain, such as the slaughterhouse and the processing plant. The line losses are the same whether or not there is methanation plant on the farm in the considered value chain. Finally, the contribution analysis Tables (2 to 5) show that all the values of environmental indicators are lowered thanks to the introduction of the methanation 
plant, in particular upstream at the level of the farm. However, since the indicators are lowered for all players in the value chain, the share allocated to farmers increases while they are responsible for $85 \%$ of the environmental impacts in our model (control scenario). We discuss in the next section how this argument can be used in favor of the farmer in the negotiation between the actors in the context of a methanation scenario introduction.

\section{DISCUSSION}

The aim of this study was to discuss two hypotheses: first how modeling a value chain and its environmental, economic and social assessment offers a systemic framework and secondly how this kind of model offers a common basis to build new cognitive knowledge. The results show that, within the scope of our study and within the limit of the indicators chosen, the methanation plant solution decreases the impact on a large majority of environmental indicators. When these indicators are not diminished, at worst they are unchanged. On the other hand, a large majority of social and economic indicators remain unchanged. A small share is worsened at the breeder step: additional working time, investments and the cost of production per product. The investment is inevitable in the case of the installation of a methanation plant but depending on the case, the return on investment can be more or less long and the investment more or less subsidized. The question of return on investment will be difficult to discuss to validate our assumptions. The ROI is not presented in this table and will be effectively dependent on each scenario. However, it is an argument to be exchanged in the context of negotiation among the partners. This provides the elements that can eventually be incorporated into the content of the contracts that will be established between the actors. The indicator 'Working time' must be analyzed in that sense: in our perimeter, its modification is related to the farmer's activity, which implies that he must no longer be paid only for the finished product which he helps to put into market but also for the services he rendered to the society. The type of sustainability assessment promoted here makes it possible to go further than with eco-labels. It can help to apprehend socio-economic services that extend and are justified considering the added value created by the farmer and its exploitation as superior than just meat production. It should also be noted that when the energy produced in the system is taken into account and sold and used off-system, the impacts are downright negative. In other words, the methanation plant solution makes it possible to compensate for certain impacts. This is also a service to the society which cannot appear in an eco-label but which is expressed in the model proposed in this article. The information provided by this case study allows going beyond a simple specification transmitted from the downstream to the upstream. The search for a solution seems to be facilitated when it goes through a co-reflection rather than a cascade of instructions. The sharing of these representations can also enable the downstream stakeholders to better understand how they can value the work carried out by the operators upstream. It was shown how services rendered to society make it possible to extend the reflection beyond what was initially envisaged in the perimeter of the value chain alone. The contribution results Tables ( 2 to 5) show us that the relative contributions change enormously when a new methanation solution is put in place in a value chain. In particular, the shares allocated to the farm are increasing sharply. However, the jobs associated with crops and livestock are already undergoing a serious economic, environmental and image crisis in society. It seems inequitable to bring costs, additional impacts to actors who are already weakened, while the solution benefits everyone in terms of image and cumulative impacts. Let us assume that the sustainability impacts of a product are brought to the attention of the consumer by means of direct or indirect traceability (on the product, the packaging, via a related website, a flashcode, a promission, etc.): 
the entire chain will be promoted, including the processor and the distributor. The benefit is not the farm but the entire value chain. It is therefore important that the risks and costs associated with setting up the scenario are shared by all players in the chain. It is reasonable to assume that, as part of the implementation of a shared methanation plant between the actors of a value chain, as in the setting up of any shared project, the responsibility of reducing the sustainability impact of this chain, costs, investments must be shared equally. Depending on the calculation of impact allocations, it is the responsibility of some of the most fragile actors to negotiate with the strongest players, often those at the downstream level, to share the benefits of image among all.

\section{CONCLUSION}

This study has shown that, in the context of the implementation of a shared methanation solution among stakeholders in a value chain, sustainability impacts are indeed reduced or maintained overall. However, on a case-by-case basis, the different contributions vary greatly with the implementation of the new scenario. The type of model developed in this article can offer a common reference framework for the actors of the value chains analyzed in order to understand the sustainability of their products and their practices from a broader perspective than they are used to. Their perimeter of responsibility is extended and this meets the expectations of consumers. It is important for the actors to co-design their improvement solutions and to associate a negotiation process between different parties and the common reference that this type of study represents thus making it possible to create and coordinate mutual knowledge. However, within the framework of the implementation of a real project and no longer a theoretical one, finer studies requiring more data are necessary in order to refine the hypotheses, and the results. On the other hand, future research remains necessary to know the prospects of mutualisation according to the type of actors studied: here the actors already work together on the sustainability of their products. One may think that this preliminary cooperation facilitated the proper introduction of the methanation plant. Would this have been the case with two actors who have never worked together or worse, with competitors? What are the limits of this work of mutualisation and structuring of the sectors?

\section{REFERENCES}

[1] Grimm, J.H., Hofstetter, J.S., Sarkis, J., Critical factors for sub-supplier management: A sustainable food supply chains perspective. International Journal of Production Economics, 152, 159-173. https://doi.org/10.1016/j.ijpe.2013.12.011

[2] Meynard, J.-M., Jeuffroy, M.-H., Le Bail, M., Lefèvre, A., Magrini, M.-B., Michon, C., Designing coupled innovations for the sustainability transition of agrifood systems. Agricultural Systems, 2016. https://doi.org/10.1016/j.agsy.2016.08.002

[3] Jolliet, O., Müller-Wenk, R., Bare, J., Brent, A., Goedkoop, M., Heijungs, R., Itsubo, N., Peña, C., Pennington, D., Potting, J., The LCIA midpoint-damage framework of the UNEP/SETAC life cycle initiative. The International Journal of Life Cycle Assessment, 9, p. 394, 2004. https://doi.org/10.1007/bf02979083

[4] UNEP/SETAC, Lignes Directrices pour l'Analyse Sociale du Cycle de Vie des Produits. Programme des Nations Unies pour l'Environnement (PNUE), 2009. 
[5] Fréard, D., Barcellini, F., Détienne, F., Baker, M. \&Burkhardt, J-M, Comprendre l'activité collaborative dans des communautés épistémiques en ligne: une approche socio-cognitive. SELF, 2012.

[6] Bucciarelli, L.L., An ethnographic perspective on engineering design. Design Studies, 9, pp. 159-168, 1988. https://doi.org/10.1016/0142-694x(88)90045-2

[7] Moletta, R., Procédés biologiques anaérobies - La digestion anaérobie des effluents. Gestion des problèmes environnementaux dans les industries agroalimentaires, ed. René, M. Tec et Doc, pp. 247-290, 2006.

[8] Bernet, N. \& Buffière, P., Caractérisation de la mise en œuvre de la méthanisation. Chapitre 3. La méthanisation. Editions Tec \& Doc Lavoisier, pp. 39-68, 2015.

[9] Kapseu, C., Nzie, W., Nso, E., Sieliechi, J. \& Ngomo H., Ngaoundéré, pp. 11-17.

[10] Godon, J.-J, Aspects biochimiques et microbiologiques de la méthanisation. Chapitre 2. La méthanisation. Editions Tec \& Doc Lavoisier, pp. 12-37, 2015.

[11] Ghouali, A., Sari, T. \& Harmand, J., Maximizing biogas production from the anaerobic digestion. Journal of Process Control, 36, pp. 79-88, 2015.

[12] Rivas, I.D.R., Modélisation de la diversité microbienne dans les procédés de digestion anaérobie. Univ. Montpellier 2 (Sciences et Techniques), p. 247, 2008.

[13] Rouillé, B., Teinturier, C., Chaabouni, R., Eudier, S., Lucas, M. \& Le Cozler, Y., Les coproduits en méthanisation: quel intérêt et quelle compétition avec l'alimentation animale?, Collection Résultats IDELE, p. 39, 2015.

[14] Battimelli, A., Carrere, H. \& Delgenes, J.P., Saponification of fatty slaughterhouse wastes for enhancing anaerobic biodegradability. 2. International Conference on Engineering for Waste Valorisation, WasteEng 2008, Patras, 2009.

[15] Rousseau, P., Etude, Modélisation et optimisation d'un procédé de traitement des lisiers de porcs par couplage de la digestion anaérobie et du traitement biologique de l'azote. Université de Rennes, 1, p. 215, 2009.

[16] Sialve, B., Bernet, N., Carrere, H., Prétraitements thermiques des lisiers : impact sur la cinétique et le taux de conversion en méthane. XIIIème Congrès de la Société Française de Génie des Procédés. Lavoisier Editions, Lille, pp. Axx1-Axx7, 2011.

[17] Jeannequin, B., Plénet, D., Carlin, F., Chauvin, J.-E. \& Dosba, F., Réduire les pertes alimentaires dans les filières Fruits, Légumes et Pomme de terre. CIAG 2014 : Carrefours de l'Innov. Agro. «Associations Végétales», Paris, p. 138, $2015 \mathrm{~b}$.

[18] Rouille, B., Le Cozler, Y., Chaabouni, R., Eudier, S., Lucas, M. \& Thual, J., Recensement des pratiques d'utilisation des coproduits par les éleveurs méthaniseurs en France. Rencontres autour des Recherches sur les Ruminants. IDELE - INRA, Paris, p. $188,2015$.

[19] Buffière, P. \& Frédéric, S., Les technologies de la méthanisation des résidus solides. Eau, l'Industrie, les Nuisances, pp. 14-19, 2008.

[20] Abbassi-Guendouz,A.,Trably,E.,Dumas,C.,Brockmann,D.,Steyer,J.-P.,Delgenès,J.-P.\& Escudié, R., Rôle du transfert de matière dans la limitation de la digestion anaérobie par voie sèche. XIVe congrès SFGP 2013. SFGP, Société Française de Génie des Procédés, Lyon, pp. 1-7, 2013.

[21] Bernet, N. \& Buffière, P., Caractérisation de la mise en ceuvre de la méthanisation. La méthanisation. Editions Tec \& Doc Lavoisier, pp. 87-113, 2011. 
[22] Levasseur, P., Aubert, P., Berger, S., Charpiot, A., Damiano, A., Meier, V. \& Quideau, P., Développement d'un calculateur pour déterminer l'intérêt technico-économique de la méthanisation dans les différents systèmes de productions animales: Méthasim, 2011.

[23] Petit, G., Bertoluci, G., Trystram, G., Lecomte, C. \& Chapdaniel, A., Innovations in attractive and sustainable food for health. 28th EFFoST International Conference, 7th International Food Factory for the Future Conference, 2014.

[24] Agence Française De L'environnement Et De La Maîtrise De L'énergie (Ademe), Pertes et gaspillages alimentaires : L'etat des lieux et leur gestion par etapes de la chaine alimentaire - Rapport. p. 164, 2016.

[25] Nielsen, 2014. Nielsen trends résultats au 26 janvier 2014. 